\title{
ON THE SUBJECT-PREDICATE STRUCTURE OF PSEUDOCLEFTS
}

\author{
NANCY A. HEDBERG \\ Simon Fraser University
}

\section{Introduction}

The purpose of this paper is to re-examine some recent analyses of pseudoclefts, focusing on claims made concerning their basic subjectpredicate structure.

I will use the term "pseudocleft clause" for the pre-copular, freerelative clause of the pseudocleft construction illustrated in (1b), and the term "clefted constituent" for the post-copular, focused constituent.

(1) a. Q: What does Mike drink?

b. A: What Mike drinks is tea.

c. $\quad$ pseudocleft clause + copula + clefted constituent

These two components can also occur in reverse order, to communicate the same message in response to the same question. I will use the term "inverted pseudocleft" when the clefted constituent precedes the pseudocleft clause, as in (2b):

(2) a. Q: What does Mike drink?

b. A: Tea is what Mike drinks.

c. clefted constituent + copula + pseudocleft clause

I will be primarily interested here in the question of which component is the "structural subject" of the sentence, i.e., the 
constituent that would be formally analyzed as the surface subject, Sstructure specifier of IP, final-1, etc. depending on particular theoretical assumptions. The perhaps most transparent analysis is to view the pseudocleft clause as the structural subject, and the clefted constituent as the "structural predicate", i.e., the main predicator (primary lexical contributor to the VP). For inverted pseudoclefts, the reverse analysis is most transparent-to view the clefted constituent as the structural subject, and the pseudocleft clause as the structural predicate.

After first briefly reviewing some recent theoretical treatments of pseudoclefts that challenge the assumption of the analysis just sketched that the pseudocleft clause is the structural subject in non-inverted specificational pseudoclefts, I will examine a subset of the empirical arguments that have been offered in support of these recent treatments, and attempt to challenge them on empirical grounds. I will close by offering some additional arguments in support of the original analysis.

\subsection{Specificational and predicational copular sentences}

As background for the discussion to follow, it is relevant to recall from the syntactic literature of the past three decades that the pseudocleft structure in (3a) is ambiguous:

(3) a. What I don't eat is food for the dog.

b. I don't eat dog food.

(specificational reading)

c. The dog eats my leftovers.

(predicational reading)

In uttering (3a), an example from Akmajian (1970), the speaker might on the one hand be identifying what it is that she doesn't eat, communicating that she doesn't eat dog food-this is often termed the "specificational" interpretation. On the other hand, the speaker might be attributing dog food status to the stuff that she doesn't eat, communicating that she gives all her leftovers to her dog - this is often termed the "predicational" interpretation.

Specificational/predicational ambiguities are not restricted to pseudocleft structures. They are also found in simple, non-clefted 
copular sentences containing definite descriptions in initial position. Thus, (4a) either identifies the winner as a certain lawyer, or else attributes the role of lawyer to a uniquely identifiable winner.

(4) a. The winner is a lawyer.

b. A certain lawyer won.

(specificational reading)

c. The winner practices law.

(predicational reading)

\subsection{Connectedness effects}

As is well known, specificational and predicational constructions can be distinguished syntactically in that specificational but not predicational sentences exhibit "syntactic connectedness" (Higgins 1973) or "reconstruction" effects. For example, a reflexive or reciprocal pronoun inside a clefted constituent may be bound and thereby licensed by an antecedent embedded in the pseudocleft clause, and such a sentence is unambiguously specificational. So we get the contrast shown in (5), where (5a) is a relevant response to a question concerning John's personality characteristics, communicating perhaps that he's arrogant-a specificational interpretation; while (5b), with him understood as coreferential with John, is a relevant response to a question concerning John's priorities - an unambiguously predicational interpretation.

(5) a. What John is is important to himself.

b. What $\mathrm{John}_{\mathrm{i}}$ is is important to himi.

This minimal pair (from Williams 1983, inter alia) is featured in the recent theoretical treatments of the structure of pseudoclefts to be discussed below.

The data in (6) illustrate a second connectedness effect - a negative polarity item in the clefted constituent may be licensed by a negative element embedded in the pseudocleft clause. Such a sentence is again unambiguously specificational. 
(6) a. What I don't have is any money

b. *What I have is any money.

\subsection{Lexically ambiguous copula}

A traditional approach to the structure of pseudoclefts is to view the specificational/predicational distinction as arising from a lexical ambiguity associated with the copula. Specificational sentences are viewed as containing an "identificational copula," exemplified most clearly in identity statements like (7a), and predicational sentences as containing a "predicational copula," exemplified most clearly in predicate-adjective sentences like (7b).

(7) a. Superman is Clark Kent.

(identificational copula)

b. Superman is strong.

(predicational copula)

One generalization that follows nicely on this approach is the general reversability of identity and specificational sentences, and the corresponding non-reversability of predicational sentences, as shown in (8a-b). Similarly, specificational pseudoclefts have inverted pseudocleft paraphrases, while predicational pseudoclefts do not, as shown in $(8 c-d)$.

(8) a. Clark Kent is Superman.

b. *Strong is Superman.

c. Important to himself is what John is.

d. *Important to himi is what $\mathrm{John}_{\mathrm{i}}$ is.

By attributing the distinction between specificational and predicational copular sentences to a lexical ambiguity, the differences between such sentences can be captured, but not the similarities. In recent years there have been at least three attempts to develop a more unified account.

\section{Recent analyses}




\subsection{Partee's analysis}

The task is approached semantically in Partee (1987). On her account, a single, univocal copula appears in all copular sentences, and this copula exhibits the special property of subcategorizing for one referential argument and one predicative argument while imposing no restriction on the mapping of these arguments onto structural positions. Initial surfacing of the predicative argument results in the specificational pseudocleft in (9a), while initial surfacing of the referential argument results in the specificational inverted pseudocleft in $(9 b){ }^{1}$

(9) a. What Mike drinks is tea.

$<e, t>\quad e$

b. Tea is what Mike drinks.

e $\quad<\mathrm{e}, \mathrm{t}>$

In predicational pseudoclefts, on the other hand, the pre-copular freerelative clause serves as the referential argument, and the post-copular constituent, as the predicative argument. Thus, instead of locating the specificational/predicational ambiguity in the copula per se, Partee locates it in the semantic character of the copula's arguments.

Partee remains neutral on the issue of the syntactic structure of copular sentences. Her analysis is perfectly compatible with the

\footnotetext{
${ }^{1}$ The symbols ' $\mathrm{e}$ ' and '<e,t>' denote the semantic types of referential and predicative expressions, respectively. It should be noted that Partee generalizes the semantic type of the copula to relate any two arguments of the types ' $\mathrm{X}$ ' and ' $<\mathrm{X}, \mathrm{t}\rangle$ ' so as to account for higher-order specificational and predicational sentences. Note also that if the compositional "destiny" of a lexical item is encoded in its semantic type, as is commonly assumed in Montague-style semantics, then, as Jacobson (1990: 31, fn. 7) points out:

If we take the '[structural] subject' to always be the last item in the semantic composition, this means that there are two (related) verbs be. One has a meaning of type $<<\mathrm{X}, \mathrm{t}\rangle,\langle\mathrm{X}, \mathrm{t}>>$ (this is the $b e$ in predicational sentences) and the meaning of the other is of type $<\mathrm{X},<<\mathrm{X}, \mathrm{t}>, \mathrm{t}>>$ (this is the be of specificational sentences).
} 
subject-predicate structure that I advocate for specificational pseudoclefts. Since the other two recent treatments of pseudoclefts involve syntactic assumptions that depart from this analysis, I will focus on them in the remainder of the present paper.

\subsection{Williams' analysis}

Partee's tactic of analyzing the specificational pseudocleft clause as a predicative expression rather than a referential one is drawn from an earlier treatment of pseudoclefts in Williams (1983). It follows from the assumption that the specificational cleft clause is a predicative expression, and Williams' general assumption that a predicative expression must be c-commanded by its subject at surface structure, that the clefted constituent must c-command the specificational pseudocleft clause. Williams thus concludes that the specificational pseudocleft clause is the structural predicate rather than the structural subject. $^{2}$

To account, then, for why the specificational pseudocleft clause appears in pre-copular position, Williams postulates that specificational pseudoclefts such as (10a) are transformationally derived from more basic inverted pseudocleft structures such as (10b), through application of the stylistic permutation rule "inversion around be,' which also produces (10c) as a stylistically-marked variant of (10d).

(10) a. What Mike drinks is tea.

b. Tea is what Mike drinks.

c. Happy is the man who sleeps.

d. The man who sleeps is happy.

\footnotetext{
2It is worth emphasizing that the notion "predicative expression" and its associated "subject" is not identical to the notion "structural predicate" of a clause and its associated "structural subject," which I have been speaking of more generally. Whereas Partee makes no syntactic claims relating predicative expressions to structural predicates, Williams makes the syntactic claim that the class of predicative expressions properly includes the class of structural predicates. His ccommand-sensitive predication rule applies to the entire class.
} 
Crucially, Williams posits that the inversion-around-be rule applies at a post-surface-structure level of derivation-specifically, after the ccommand-sensitive rule of "predication" has applied. In support of this analysis, he offers a number of data paradigms that he claims indicate that specificational pseudocleft clauses lack essential structural-subject properties. I will return to these arguments after introducing the third recent treatment of pseudoclefts.

\subsection{Heggie's analysis}

A unified syntactic account of copular sentences is developed in Heggie (1988). Heggie proposes that inverted and non-inverted specificational pseudoclefts derive from a common deep-structure configuration in which the clefted constituent is the subject and the pseudocleft clause the predicate, of a small-clause complement to the copula. Both types of specificational pseudocleft are derived by moving the small-clause subject into pre-copular structural-subject position-i.e., into the specifier position of IP. To derive non-inverted pseudoclefts, a further preposing of the pseudocleft clause into the specifier position of $\mathrm{CP}$ takes place, which in turn triggers subjectauxiliary inversion.

Heggie thus treats the non-inverted pseudocleft in (11a) as structurally parallel to the wh-question in (11b) and to the negativepreposing construction in $(11 \mathrm{c})$, both of which also trigger subjectauxiliary inversion. The surface-structure configurations that Heggie posits are shown in (12).

(11) a. What Mike drinks is tea.

b. What is Mike drinking?

c. Not only tea is Mike drinking.

(12) a. [CP [what Mike drinks $]_{\mathrm{i}}\left[\mathrm{C}^{\prime},\left[\mathrm{C}^{\mathrm{O}}\right.\right.$ is $] \mathrm{k}$ [IP tea $\left.\left.\mathrm{t}_{\mathrm{k}} \mathrm{t}_{\mathrm{i}}\right]\right]$

b. [CP [what $]_{\mathrm{i}}\left[\mathrm{C}^{\prime}\left[\mathrm{C}^{\mathrm{O}} \text { is }\right]_{\mathrm{k}}\right.$ [IP Mike $\mathrm{t}_{\mathrm{k}}$ drinking $\left.\left.\left.\mathrm{t}_{\mathrm{i}}\right]\right]\right]$ 
c. $\left[\mathrm{CP}[\text { not only tea }]_{\mathrm{i}}\left[\mathrm{C}^{\prime}\left[\mathrm{C}^{\mathrm{O}} \text { is }\right]_{\mathrm{k}}\right.\right.$ [IP Mike $\mathrm{t}_{\mathrm{k}}$ drinking $\left.\left.\left.\mathrm{t}_{\mathrm{i}}\right]\right]\right]$

What Williams' and Heggie's approaches have in common is the claim that the pseudocleft clause in a non-inverted specificational pseudocleft is in fact the structural predicate of the sentence rather than the structural subject. For Heggie as well as Williams it is instead the clefted constituent which is the structural subject. Both Williams and Heggie offer data paradigms in support of this claim, which they intepret as showing that initial pseudocleft clauses lack syntactic subject properties. I will now turn to a critical examination of these arguments.

\section{Alleged Non-subject Properties of the Pseudocleft Clause}

Although Williams and Heggie present several arguments, I have space here to examine only three. It is relevant to recall, as they do, that most of their arguments and the grammaticality judgments that they crucially rely on originated in Higgins (1973) and Hankamer (1974). Neither Williams nor Heggie, however, discuss the criticisms of those arguments that were published in Gundel (1977), Culicover (1977), and Halvorsen (1978).

\subsection{Subject-auxiliary inversion.}

Williams and Heggie offer the judgments in (13a-b) as support for the conclusion that pseudocleft clauses fail to undergo subject-auxiliary inversion, and thus do not behave like ordinary structural subjects. In 1974, Hankamer offered the judgments in (13c-d) in support of the same claim. However, in 1977, Culicover offered the judgments in (13e-f) as counterexamples to Hankamer's claim.

(13) a. *Is what John is important to himself?

b. Is important to himself what John is?

c. *Was what John said that we should all go home?

d. *Was what Mary did (to) wash herself?

e. Will what John says be that we should all go home? 
f. Will what Mary does be to wash herself?

Inclusion of the future auxiliary does indeed seem to improve the examples, perhaps because it is easier to imagine a context in which such a question would be relevant-i.e., one in which the speaker does not already know the answer to the question evoked in the pseudocleft clause and believes that the addressee does. Explicitly contrastive and negative questions such as (14a-b), both of which evoke a constrained set of alternatives, are even less awkward.

(14) a. Is what you're writing on clefts or pseudoclefts?

b. Isn't where he's going San Francisco?

To be fully felicitous, it may be that a pseudocleft subject of a yes-no question should currently be under discussion. But this requirement clashes with the typical function of initial pseudocleft clauses to introduce or reintroduce new topics for discussion (c.f. Delin 1989; Hedberg 1990).

The contrast between the relative strength of the unacceptability of the inversion-around-be questions in (15) with the relative weakness of the unacceptability of the pseudocleft questions in (14), casts further doubt on Williams' attempt to identify the two constructions:

(15) a. *Is happy the man who sleeps or the man who dreams?

b. *Isn't happy the man who sleeps?

\subsection{Raising constructions.}

Williams and Heggie also resurrect judgments from Higgins (e.g. (16c)) and Hankamer (e.g. (16d)) indicating that "subject-to-subject raising' variants of non-inverted specificational pseudoclefts are ungrammatical.

(16) a. Important to himself seems to be what John is. 
b. *What John is seems to be important to himself.

c. *What John is tends to be conceited.

d. *What he was doing turned out to be washing himself.

Convincing counterexamples to Higgins and Hankamer's claims were again offered by later researchers. Thus Gundel (1977) offered (17a), Culicover (1977), (17b), and Halvorsen (1978), (17c).

(17) a. What he's asking appears to be whether there will be any beer.

b. What John is seems to be proud of himself.

c. What John wants seems to be never to be left alone.

The good cases all appear to involve pseudoclefts whose semantic content is such as to make it plausible to mitigate or intensify the epistemic force of the specification performed by the pseudocleft. Note also the specification sentences in (18):

(18) a. What he's after seems to be her money.

b. With or without Cuomo as the Democratic candidate, the winner in November is certain to be George Bush.

Any deviance felt to be associated with the sentences in (16) should thus be attributed to semantic or pragmatic rather than to syntactic factors. ${ }^{3}$ And once again, the deviance of (19) shows that inversionaround-be is less compatible with raising than with pseudoclefting.

(19) a. *Happy seems to be the man who sleeps.

b. *Happy turns out to be the man who sleeps.

\subsection{Gapping.}

3Note that parallel refutations can be constructed for Higgins' (1973) suggestions that modal auxiliaries and sentential adverbs are also unacceptable in non-inverted pseudoclefts. 
Non-inverted pseudoclefts have also been claimed to be ungrammatical in "gapping" constructions. The judgment in (20a-b) is from Williams (1983), and that in (20c) is from Higgins (1973). Williams points out, however, that gapping of inverted pseudoclefts like (20b) and (20d) is readily acceptable.

(20) a. *What John is is important to himself and what Mary is, important to herself.

b. Important to himself is what John is and important to herself, what Mary is.

c. *What John is is stupid and what Bill is, proud.

d. Stupid is what John is and proud, what Bill is.

He argues that this paradigm supports his analysis since the rule of gapping bleeds application of the inversion-around-be rule. However, apparent counterexamples can again be constructed, as in (21)-(22).

(21) a. Q: So, what DID Bill sketch, and what DID Mary sketch?

b. A: What Bill sketched was a picture of himself, and what Mary sketched, a picture of Bill.

(22) a. Q: So, what DOES Jane want, and what DOES Bill want?

b. A: What Jane wants is never to go out, and what Bill wants, never to stay home.

I suggest that the differences between the good cases and the bad cases can be attributed to discourse pragmatic factors. The more contrastive the content of the pseudocleft clause and clefted constituent, the better the example. Since on the one hand, remnants of gapping must represent "new information" (Kuno 1976), and on the other hand, initial pseudocleft clauses must express sentence topics (c.f. Hedberg 1990), an initial pseudocleft clause can satisfy both these constraints 
only by expressing a contrastive topic, as in (21)-(22). ${ }^{4}$ Higgins' and Williams' examples in (20a) and (20c), remain unacceptable, however, even when embedded in contexts where the pseudocleft clauses are construable as contrastive topics, perhaps because a relevant dimension of contrast for the clefted constituent is less accessible here than in (21)-(22). Prince (1988) observes that the remnants of gapping must instantiate variables in "an open proposition taken to be shared knowledge." It seems, thus, that the presuppositions "each of them wants something" and "each of them drew something" are more likely to satisfy this constraint than the open proposition "each of them are something". In other words, the topical question that would elicit (20a) or (20c) as an appropriate answer-i.e., "What IS Bill, and what IS Mary?" - is unlikely to be relevant.

Note also that while some of the speakers I consulted reject the gapped specificational pseudoclefts in (21b) and (22b), they all accept specificational copular sentences with definite descriptions in initial position, as in (23b):

(23) a. Q: So, what IS Mary's biggest problem, and what IS John's biggest problem?

b. A: John's biggest problem is a fear of his mother, and Mary's biggest problem, a fear of herself.

Since the post-copular constituent in (23b) contains a reflexive pronoun whose antecedent is embedded in the pre-copular definite description, Williams would have to analyze (23b) as another instance of the inversion-around-be construction, in order to satisfy his assumption (p. 430) that "a subject is 'syntactically connected' to its predicate (and not vice versa)." Thus his analysis would fail to account for its apparent grammaticality.

${ }^{4}$ Compare Prince (1988: 177-178): "The leftmost constituents of gapped clauses represent backward-looking centers.... The backward-looking center must be in a set relation, not simply evoked in the discourse." 


\section{Subject Properties of the Pseudocleft Clause}

I conclude from the data just reviewed that all of the arguments offered by Williams and Heggie to support the claim that specificational pseudocleft clauses lack structural subject properties fail on empirical grounds. It must be admitted, however, that the instability of the critical grammaticality judgments potentially undermines my attempted refutations.

\subsection{Tag questions.}

I now turn to a new argument that crucially relies on robust grammaticality judgments in support of the conclusion that specificational pseudocleft clauses do exhibit structural subject properties. Examples (24a-b) show that tag-questioned specificational pseudoclefts are perfectly acceptable. Furthermore, $(24 c-d)$ show that the tag pronoun necessarily corefers with the pre-copular pseudocleft clause, and not the post-copular clefted constituent.

(24) a. What they bought was books, wasn't it?

b. The one they really want to hire is Tom, isn't it?

c. *What they bought was books, wasn't/weren't they?

d. *The one they really want to hire is Tom, isn't he?

No analysis that fails to treat the pseudocleft clause as the structural subject in specificational pseudoclefts is compatible with the apparently uncontroversial assumption that the element echoed in an interrogative tag is the structural subject of the sentence.

The paradigms in (24) and (25) clearly distinguish pseudoclefts from inversion-around-be sentences, and are consistent with the analysis of the pre-copular constituent as the structural subject in specificational pseudoclefts, and the post-copular constituent as the structural subject in inversion-around-be sentences.

(25) a. *Happy is the man who sleeps, isn't it?

b. Happy is the man who sleeps, isn't he? 


\subsection{Multiple auxiliary verbs}

Heggie's analysis of the medial position of the copula in non-inverted specificational pseudoclefts as arising from subject-auxiliary inversion would be undermined by data indicating that more than one auxiliary verb can accompany the copula in medial position in pseudoclefts, since only the first auxiliary verb is ever inverted with the subject via subjectauxiliary inversion. Heggie relies once again on Higgins' judgments that auxiliary verbs are not possible in non-inverted pseudoclefts, offering the examples shown in (26).

(26) a. *What John is may be rich.

b. *What John is should be important to himself.

Counterexamples are once again easy to construct, and it is even possible to find them fairly regularly in natural discourse. Examples that are perfectly acceptable are shown in (27). Note that (27b-c) illustrate the fairly common occurence of doubling the future auxiliary of a pseudocleft clause in the matrix clause.

(27) a. What Peter wanted must have been revenge.

b. But what really may be at issue when this comes to term will be deployment of SDI. [McLaughlin Group, 11/27/87]

c. What Soviets will gain from reading Dr. Zhivago will be a somewhat better understanding of their recent history.

[Minneapolis Tribune, 1/30/87]

The contrasting paradigms in (28) and (29) show clearly that Heggie's assimilation of specificational pseudoclefts to constructions that trigger subject-auxiliary inversion is unsuccessful.

(28) a. What Mike will be drinking will be tea.

b. *What will be Mike drinking?

c. *Not only tea will be Mike drinking. 
(29) a. *What Mike will be drinking will tea be.

b. What will Mike be drinking?

c. Not only tea will Mike be drinking.

In wh-questions and negative preposing constructions, the first and only the first auxiliary verb precedes the subject, a pattern contradicted in pseudoclefts. These paradigms are, however, consistent with my conclusion that the pseudocleft clause is the structural subject of a specificational pseudocleft.

\section{Conclusion}

I have argued in this paper that contrary to the analyses of Williams (1983) and Heggie (1988), the pseudocleft clause rather than the clefted constituent is the structural subject in non-inverted specificational pseudoclefts. Note, however, that it is still possible to analyze noninverted specificational pseudoclefts as syntactically derived from more basic inverted pseudocleft structures, and thus preserve the unifying spirit of the Williams-Partee-Heggie account, by assuming the derivation to involve a process analogous to passivization, as proposed in Halliday (1985).

It is not yet clear to me, however, that the traditional analysis, which locates the source of the specificational-predicational distinction in a lexical ambiguity of the copula, should be abandoned. First, there is apparently at least one natural language that has morphologically distinct identificational and predicational copulas-namely, Thai (Kuno \& Wongkhomthong 1981). Secondly, there is a promising alternative to the Williams-Partee-Heggie account of the difference between "superscriptional" and "referential" arguments of specificational sentences (c.f. Higgins 1973) as involving the distinction between non-referring, "predicative" expressions and referring expressions. It appears plausible to instead analyze the difference as involving the distinction between "attributive" and "referential" referring expressions in the sense of Donnellan (1966), as 
suggested in Gundel (1977). However, exploration and comparison of these alternatives must await further research.

\section{REFERENCES}

Akmajian, Adrian. 1970. Aspects of the Grammar of Focus in English. Ph.D diss., Massachusetts Institute of Technology.

Culicover, P[eter] W. 1977. "Some Observations Concerning Pseudoclefts." Linguistic Analysis 3:347-375.

Delin, J[udy] L. 1989. Cleft Constructions in Discourse. Ph.D. diss., University of Edinburgh.

Donnellan, Keith. 1966. "Reference and Definite Descriptions." Philosophical Review 75:281-304.

Gundel, Jeanette K. 1977. "Where do Cleft Sentences Come From?" Language 53:543-559.

Halliday, M[ichael] A. K. 1985. An Introduction to Functional Grammar. London \& Sydney, Australia: Edward Arnold.

Halvorsen, Per-Kristian. 1978. The Syntax and Semantics of Cleft Constructions. Ph.D. diss., University of Texas, Austin.

Hankamer, Jorge. 1974. "On the Non-cyclic Nature of Wh-clefting." Papers from the Tenth Regional Meeting of the Chicago Linguistic Society, ed. by 221-233.

Hedberg, Nancy A. 1990. Discourse Pragmatics and Cleft Sentences in English. Ph.D diss., University of Minnesota, Minneapolis.

Heggie, Lorie A. 1988. The Syntax of Copular Structures. Ph.D. diss., University of Southern California, Los Angeles.

Higgins, F[rancis] Roger. 1973. The Pseudo-Cleft Construction in English. Ph.D diss., Massachusetts Institute of Technology.

Jacobson, Pauline. 1990. "On the Quantificational Force of English Free Relatives." Ms., Brown University.

Kuno, Susumo.1976. "Gapping: A functional analysis." Linguistic Inquiry 7:300-318. 
Kuno, Susumo \& P. Wongkhomthong. 1981. "Characterizational and Identificational Sentences in Thai." Studies in Language 5.65-109.

Partee, Barbara H. 1987. "Noun Phrase Interpretation and Typeshifting Principles." In Studies in Discourse Representation Theory and the Theory of Generalized Quantifiers, ed. by J. Groenendijk and M. Stokhof, 115-143. Dordrecht: Foris.

Prince, Ellen F. 1988. "Discourse Analysis: A part of the study of linguistic competence." In Linguistic Theory: Extension and Implications., ed. by Frederick J. Newmeyer,164-182. Cambridge: Cambridge University Press.

Williams, Edwin. 1983. "Semantic vs. Syntactic Categories." Linguistics and Philosophy 6:423-446. 